\title{
Heat transfer and fluid flow characteristics of rib- groove roughened solar air heater ducts
}

\author{
C.B.Pawar ${ }^{1}$, K.R. Aharwal ${ }^{1}$ and Alok Chaube $^{2}$ \\ ${ }^{1}$ Dept. of Mech. Engg,, Shri. G.S. Instt. of Technol. \& Sc., Indore, ${ }^{2}$ Rajiv Gandhi Technical Univ., Bhopal, M.P., India \\ c_bpawar@rediffmail.com
}

\begin{abstract}
The performance of solar air heater is considerably low due to the low value of convective heat transfer coefficient between the flowing air and the absorber plate. This is due to the formation of thin viscous sub-layer at the surface of the absorber plate. Artificial roughness is used to break the laminar viscous sub-layer formed on the absorber plate for increasing the level of turbulence to enhance the heat transfer. In the present work artificial roughness in the form of integral wedge shaped rib with and without groove has been employed on one of the heated broad wall of the rectangular duct to enhance the heat transfer. The wedge angle $(\Phi)$ was varied from $10^{\circ}$ to $25^{\circ}$ for relative roughness pitch $(\mathrm{p} / \mathrm{e})$ was kept as 8 and relative roughness height (e/D) was maintained as 0.033 . The aspect ratio of the rectangular duct was maintained as 8 . The Nusselt number and friction factor of the artificially roughened ducts were determined experimentally and the corresponding values were compared with that of smooth duct for the range of Reynolds number 3000-20000. The maximum enhancement in heat transfer was observed for the artificial roughness of wedge angle $15^{\circ}$. At the optimum angle of $15^{\circ}$ a groove was incorporated. It was observed that wedge-groove roughened surface shows more enhancement in heat transfer compared to only rib roughened surface. The investigation revealed that Nusselt number increases 1.5-3 times of the smooth duct while the friction factor increases two to three folds that of the smooth duct in the range of operating parameters. The uncertainties in the measurements due to various instruments for the Reynolds number, Nusselt number and friction factor lies in the range of $\pm 3.8 \%, \pm 3.54 \%$, and $\pm 7.6 \%$, respectively.
\end{abstract}

Keywords: Nusselt number, Reynolds number, friction factor, solar heater, dryer.

\section{Nomenclature}

$A_{p}=$ Area of the absorber plate, $\mathrm{m}^{2} ; \mathrm{D}=$ Equivalent hydraulic diameter, $\mathrm{m} ; \mathrm{e}=$ Rib height, $\mathrm{m} ; f_{\mathrm{s}}=$ Friction factor of smooth plate; $f=$ Friction factor of rough plate; $h$ $=$ Convective heat transfer coefficient, $\mathrm{W} / \mathrm{m}^{2} \mathrm{~K} ; k=$ Thermal conductivity, $\mathrm{W} / \mathrm{mK} ; \mathrm{m}=$ Mass flow rate, $\mathrm{kg} / \mathrm{s}$; $\mathrm{Nu}_{\mathrm{s}}=\quad$ Nusselt number of smooth surface; $\mathrm{Nu}=$ Nusselt number of rough surface; $p=$ Pitch of the rib, $m$; $Q_{u}=$ Useful heat gain, $W ; T_{f}=$ Mean film temperature of air, $\mathrm{K} ; \mathrm{T}_{\mathrm{i}}=$ Mean Inlet temperature of air, $\mathrm{K} ; \mathrm{T}_{\mathrm{o}}=$ Mean Outlet temperature of air, $\mathrm{K} ; \mathrm{T}_{\mathrm{p}}=$ Average plate temperature of air, $\mathrm{K} ; \rho=$ Density of air, $\mathrm{kg} / \mathrm{m}^{3} ; \Delta \mathrm{p}=$ Pressure drop across test section, $\mathrm{Pa} ; \mathrm{V}=$ Velocity of air, $\mathrm{m} / \mathrm{s}$.

\section{Introduction}

Enhancement of heat transfer in internal passages is always preferred in variety of applications like combustion chamber, cooling of gas turbine blades, compact heat exchangers and solar air heater etc. Several attempts have been made on enhancement of heat transfer which is broadly classified in two categories namely active and passive techniques. One of the well known passive methods of enhancing the heat transfer is to roughen the heat transfer surface artificially by the use of repeated transverse or inclined ribs to the flow. Many researchers (Williams et al., 1970; Webb et al., 1971; Han et al.,1978) have developed co-relations to investigate the effects of rib shape, pitch to height ratio $(\mathrm{p} / \mathrm{e})$ on friction factor and heat transfer. They concluded that the rib cross section has marked effect on the friction and modest effect on heat transfer. Also, ribbed angle effect decreased as the aspect ratio of the duct increased. The concept of combined turbulence promoters' rib-groove arrangement on the absorber plate was introduced by Zhang et al (1994). They reported that the enhancement in the heat transfer for rib-grooved surface was better than only rib roughened surface.

For the application of artificial roughness for enhancing the heat transfer in solar air heater, where the insolation are received only on one side i.e. upper surface, only that surface is to be roughened, while the remaining three walls should be kept insulated. Thus, the application of artificial roughness in solar air heater makes the fluid flow and heat transfer characteristics distinctly different than those found in case of two roughened wall surface of a rectangular channel. Prasad et al. (2009) used wire mesh to enhance the heat transfer of solar air heater and concluded that the enhancement in heat transfer is a strong function of mass flow rate and the porosity of the bed. Prasad \& Saini (1988) investigated the heat transfer and friction factor in solar air heater using transverse ribs made of copper, glued on the absorber plate. They concluded that increasing p/e ratio ( $p$ is the pitch of ribs) beyond about 10 decreases the enhancement in heat transfer. Jaurker et al. (2006) investigated the rib-groove (square rib and triangular groove) roughness arrangement and reported that the heat transfer enhances by 2.75 time and friction factor increased by 3-3.5 times compared to that of the smooth surface. In another study (Layek et al., 2007), the effect of chamfered rib with and without groove was investigated and concluded that the increase in heat transfer coefficient and friction factor for the rib-groove roughness was higher than that of the rib roughness only. Hassan Ridouane \& Campo (2008) performed the numerical
Research article

CIndian Society for Education and Environment (iSee)
"Heat transfer efficiency in solar dryer" http://www.indjst.org
Pawar et al. Indian J.Sci.Technol. 
study for investigating the convective heat transfer over a plate maintained at a constant temperature and concluded that the flow recirculation zone exist in each groove and vortices get stronger near the groove leading to local heat flow augmentation there by increasing the surface and average Nusselt number. Bhagoria et al. (2002) reported the heat transfer and friction factor for wedge shaped rib roughened surface for e/D $0.015-0.033$ and p/e ratio of 6- 12 and also determined the optimum angle for the maximum heat transfer. They concluded that e/D of 0.033 and p/e of 8 shows the maximum enhancement in heat transfer of 1.22.2 compared to that of the smooth surface.

From the above discussion it is understood that the artificial roughness in the form of wedge shaped transverse rib roughened surface shows better study the effect of wedge groove roughness geometry on the heat transfer and fluid flow characteristics of a rectangular duct. A schematic diagram of experimental set up is shown in Fig.1. It consists of an entry section, test section, exit section, transition section, of internal size of $2600 \mathrm{~mm} \times 200 \mathrm{~mm} \times 25 \mathrm{~mm}$, a centrifugal blower with a control valve to regulate the mass flow rate and a flow measuring orifice-meter connected with an inclined U- tube manometer to measure the mass flow rate of air. Aluminium plate of $8 \mathrm{~mm}$ thickness having artificial roughness called the absorber is given a uniform heat flux $\left(1000 \mathrm{~W} / \mathrm{m}^{2}\right)$ by a variac controlled electrical heater. Calibrated copper-constantan thermocouples (24 SWG), having least count of $0.1^{\circ} \mathrm{C}$ are used for the temperature measurement of the absorber plate and the air inlet and outlet. The pressure drop across the length

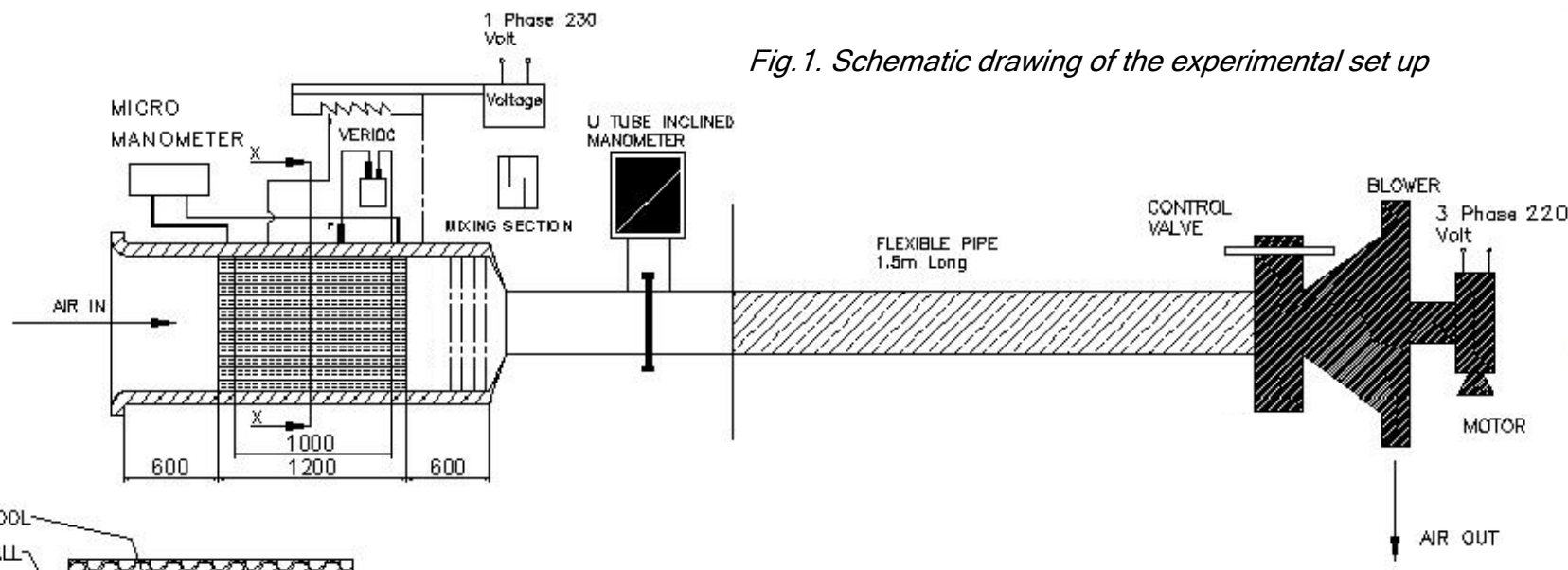

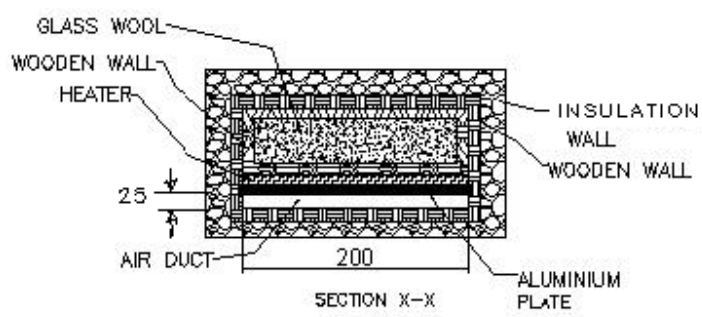

enhancement in heat transfer. Secondly, the rib and groove arrangement enhances more heat transfer compared to rib roughness only by little increase in pressure drop. Hence, the objective of the present work is to conduct experiments to investigate the effect on heat transfer and friction characteristics for artificially roughened transverse wedge shaped ribs (integral type) with and without groove arrangement of the upper broad side of the rectangular duct. In the entire experimentation the relative roughness pitch ( $\mathrm{p} / \mathrm{e}$ ) was maintained as 8 , the relative roughness height (e/D) was kept equal to 0.033 , wedge angle was varied from $10^{\circ}$ to $25^{\circ}$ in steps of five degree, groove angle of $60^{\circ}$ and groove depth equal to the rib height $(1.5 \mathrm{~mm})$ and the relative groove position (g/p) was kept as 0.65 .

Experimental set up and procedure

An experimental test facility has been designed and fabricated as per the ASHRAE recommendation 93-97 to of the test section is measured by a micro-manometer having a least count of $0.01 \mathrm{~mm}$.

The sketch of the roughness geometry used for present work (wedge shaped rib-groove roughness) is as shown in Fig.2.

In order to minimize the percentage error in measurement of temperatures, minimum heat flux value is so selected as to raise the temperature of air by about $10^{\circ} \mathrm{C}$ in the test section. The temperature difference between the heated plate and the bulk air was observed to be above $25^{\circ} \mathrm{C}$. The airflow rate was varied to give the flow having a range of Reynolds number in the range of 3000 to 20,000 .

Relevant data were noted under the steady-state condition for constant surface heat flux, which was assumed to have reached when the plate and air temperatures shows negligible variation for about 10-
Research article

CIndian Society for Education and Environment (iSee)
"Heat transfer efficiency in solar dryer" http://www.indjst.org
Pawar et al. Indian J.Sci.Technol. 
minute duration. The steady state for each test run was obtained in about 1.5 to 2 hours.

\section{Data reduction}

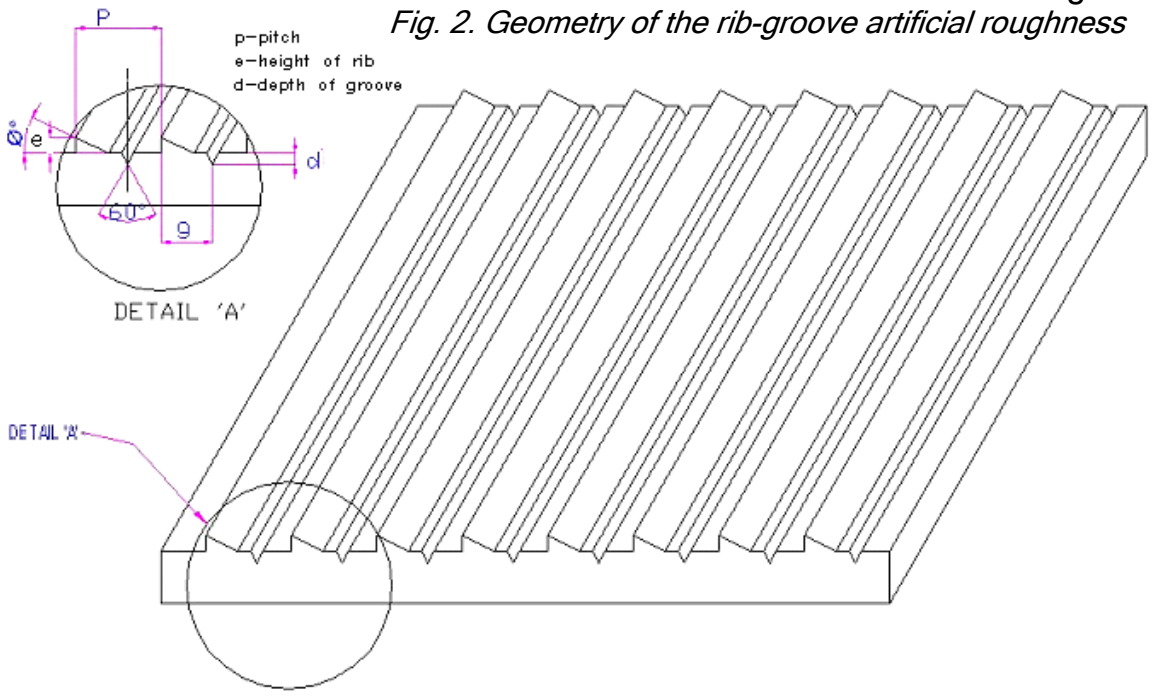

Vol.2 No. 11 (Nov. 2009)

ISSN: 0974- 6846

$$
f=\frac{2 \Delta p \cdot D}{4 \rho l \cdot V^{2}}
$$

Where, $\rho$ is density of air and $V$ is the velocity of air through the rectangular duct of the test section. The pressure drop $(\Delta p)$ across the test section along the length was measured with the help of micro-manometer in cold condition i.e. without heating the absorber plate.

\section{Validation of experimental setup}

Before taking the experimental data of artificially roughened ducts (one broad surface roughened and other three surfaces smooth), the experimental set up was validated by keeping all surface as smooth surfaces and the results obtained in the form of Nusselt number and friction factor were compared with the standard correlations for Nusselt number by Dittus and Bolter equation (5) and for friction factor by modified Blasius co-relations equation (6)

Mass flow rate $\mathrm{m}$ was determined from the pressure drop $(\triangle P)$ measured across the orifice plate as

$\mathrm{m}=\mathrm{C}_{\mathrm{d}} \mathrm{A}_{\circ} \sqrt{\frac{2 \rho(\Delta P)}{1-\beta^{4}}}$

where $A_{o}$ is cross section area of orifice, $\beta$ is the ratio of diameter an orifice to the internal diameter of pipe, $\rho$ is the density of air. The value of convective heat transfer coefficient ' $h$ ' for the test section was calculated by the following relation $h=Q_{u} / A_{p}\left(T_{p}-T_{f}\right)$ where, $Q_{u}$ the heat transfer rate to the air is given by: $Q_{u}=m C_{p}\left(T_{0}-T_{i}\right)$ $T_{p}, T_{0}, T_{i}, T_{f}$ are the average temperatures of the absorber plate, air temperature at the outlet, air temperature at inlet section, and bulk mean temperature of the air

Fig. 3. Nusselt number as function of Reynolds number for smooth surface

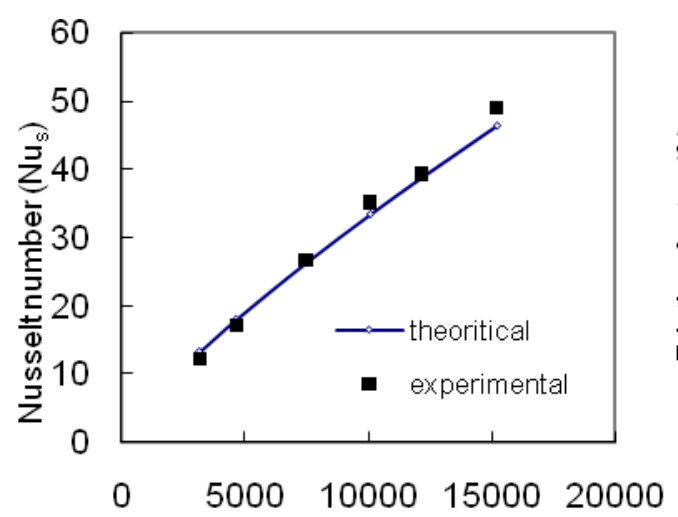

Reynolds number $(\mathrm{Re})$
$\mathrm{Nu}=0.023 \mathrm{Re}^{0.8} \mathrm{Pr}$
$f=0.085 \mathrm{Re}^{0.25}$. are as shown in Fig. 3 and 4, respectively.

It is observed that the average deviation in the experimentally investigated values of Nusselt number and friction factor, with the standard co-relation value calculated using the above relationships were within the range of $\pm 3 \%$. Thus, the results obtained and the

Fig.4 Friction factor as function of Reynolds

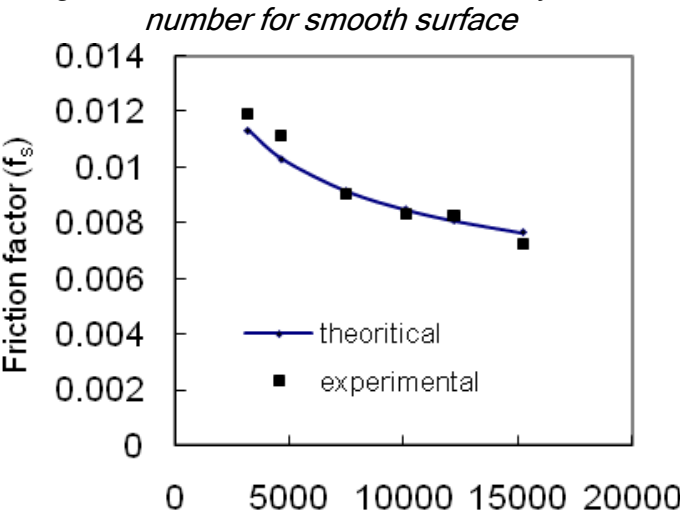

Reynolds number $(\mathrm{Re})$ respectively. $A_{p}$ is the area of the heat transfer surface. The Nusselt number was calculated by using the following relation

$\mathrm{Nu}=h \mathrm{D} / k$

where $h$ is the convective heat transfer coefficient, $D$ is the hydraulic diameter of the rectangular duct and $\mathrm{k}$ is the thermal conductivity of air.

The friction factor was determined by using the following relation the experimental set up.

\section{Results and discussions}

The effect of wedge angle and the relative groove position on heat transfer and friction factor of artificially roughened ducts have been investigated experimentally and compared with those of the smooth duct under similar operating conditions.
Research article

CIndian Society for Education and Environment (iSee)
"Heat transfer efficiency in solar dryer" http://www.indjst.org
Pawar et al. Indian J.Sci.Technol. 
Fig.5(a) shows the variation of Nusselt number as a function of Reynolds number for different values of wedge angles ranging from $10^{\circ}$ to $25^{\circ}$ in four steps (namely 10, 15, 20 and $25^{\circ}$ ) for fix values of relative roughness pitch $(\mathrm{p} / \mathrm{e})$ of 8 and relative roughness height ( $\mathrm{e} / \mathrm{D})$ of 0.033 . It was observed that in all the cases the Nusselt number increases with increase in Reynolds number. The increase in Nusselt number was more prominent at higher Reynolds number as compared to that at lower Reynolds number. It was also observed that the value of Nusselt number increases with increase in wedge angle up to $15^{\circ}$ and then decreases with further increase in the wedge angle. This may be due to the fact that when the wedge angle is nearly $15^{\circ}$ the wedge ends nearly at four times of the rib height and sufficient flat surface is available between the two consecutive ribs for the reattachment. With further increase in wedge angle the amount air bound in the recirculation zone behind the ribs increases causing hot spots there by poor heat transfer (Taucher \& Mayinger 1995). In order to bring out the effect of that wedge angle on the Nusselt number the results presented in Fig 5(a) are re-plotted for the few selected value of Reynolds number in Fig. 5(b). It is seen that for each Reynolds number the maximum value of Nusselt number is observed at nearly $15^{\circ}$ wedge angle. The maximum value of Nusselt number was observed at $15^{\circ}$ wedge angle. The value of Nusselt number increases by 1.1-2.6 times as compared to that of the smooth duct.

Fig.6. shows the variation of friction factor with Reynolds number as a function of wedge angle. It was observed that the values friction factor increases with increase in wedge angle. The value of friction factor observed for ribbed roughness arrangement increases by 2.6 times as compared to the smooth duct. (Bhagoria et al., 2002) has also reported that the value of friction factor increases with increase in wedge angle.

\section{Conclusions}

The major conclusion drawn from the investigations of heat transfer coefficient and friction factor are as follows:

- It is observed that the roughness arrangements with wedge angle of $15^{\circ}$ shows better

Research article

CIndian Society for Education and Environment (iSee)
Fig.5(b) Nusselt number as function of wedge angle for selected Reynolds number, fixed $e / D=0.033$

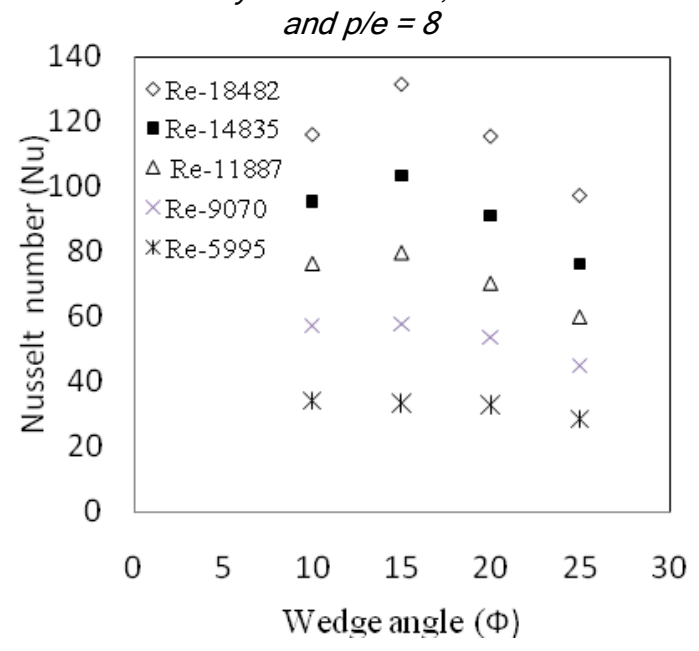

"Heat transfer efficiency in solar dryer" http://www.indjst.org
Vol.2 No. 11 (Nov. 2009)

ISSN: 0974- 6846

enhancement of heat transfer compared to the other wedge angles roughness arrangements.

- The rib-groove arrangement provides further enhancement in heat transfer compared to only rib roughened surface.

- The rib-groove arrangement provides better thermo hydraulic performance as compared to only rib roughness arrangement.

References

1. ASHRAE standards (1977) Methods of testing to determine the performance of solar air heater, 93-97.

2. Bhagoria JL, Saini JS and Solanki SC (2002) Heat transfer coefficient and friction factor correlation for rectangular solar air heater duct having transverse wedge shaped rib roughness on the absorber plate. J. Renewable Energy. 25, 341-369.

3. Duffie JA and Beckman WA (1980) Solar engineering of thermal processes. Wiely, New York.

4. Han JC, Glicksman LR and Rohsenow WM (1978) An investigation of heat transfer and friction for rib roughened surfaces. Trans. ASME J. Heat Transfer. 78, 1143-1156.

5. Hassan Ridouane El and Campo A (2008) Heat transfer enhancement of air flowing across grooved channels: joint effects of channel height and groove depth. ASME J. Heat transfer. 130./ 021901-1 to 7.

6. Jaurker AR, Saini JS and Gandhi BK (2006) Heat transfer coefficient and friction characteristics of rectangular solar air heater duct using rib-grooved artificial roughness. Intl.J. Solar Energy. 80, 895-907.

7. Kline SJ and Mc Clintock A (1953) The description of uncertainties in a single sample experiments. Mech. Engg. 75, 3-8.

8. Layek A, Saini JS and Solanki SC (2007) Heat transfer coefficient and friction characteristics of rectangular solar air heater duct using rib-grooved artificial roughness. Intl. J. Heat \& Mass Transfer. 50, 4845-4854.

9. Lewis MJ (1975) Optimizing the thermo hydraulic performance of rough surface. Intl. J. Heat \& Mass Transfer. 18, 1243 -1248. 
Fig. 7 Nusselt number Vs Reynolds number for relative groove $(g / p)=0.65 \&$ without groove, for wedge angle $15^{\circ}, e / D=0.033$ and $p / e=8$.

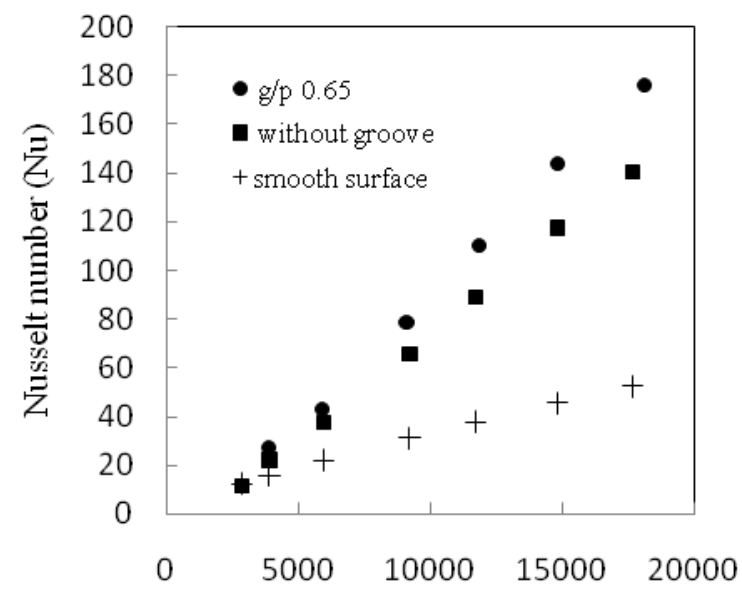

Reynolds number (Re)
Vol.2 No. 11 (Nov. 2009)

ISSN: 0974- 6846
Fig. 8. Performance index Vs Reynolds as function for wedge angle for fix value of $e / D=0.033$.

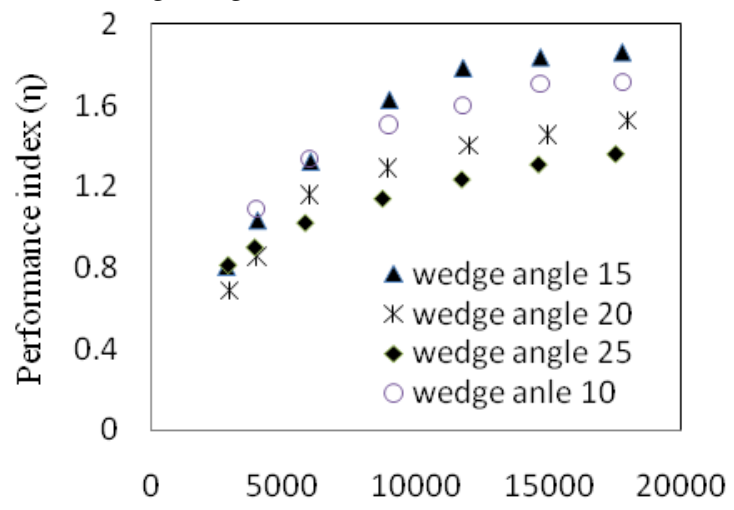

Reynolds number (Re)

10. Prasad BN and Saini JS (1988) Effect of artificial roughness on heat transfer and friction factor in a solar air heater. Solar Energy. 41 (6), 555-560.

11. Prasad SB, Saini JS and Singh Krishna M (2009) Investigation of heat transfer and friction characteristics of packed bed solar air heater using wire mesh as packing material. Intl. J. Solar energy. 83, 773-783.

12. Tauscher $R$ and Mayinger $F$ (1995) Enhancement of heat transfer in plate heat exchanger by turbulence promoters. Proc. International Conf. on Compact Heat Exchanger for the Process Industries, Snowbird, Begell House, Inc., N.Y., USA.

13. Webb RL, Eckert ERG and Goldstein RJ (1971) Heat transfer and friction in tubes with repeated rib roughness. Intl. J. Heat \& Mass Transfer. 14, 601617.

14. Williams F, Pirie MAM and Warburton C (1970) Heat transfer from surfaces roughened by ribs. $A S M E$ Symp. Volume: Augmentation of Convective Heat \& Mass Transfer.

15. Zang YM, Gu WZ and Han JC (1994) Heat transfer and friction in rectangular channel with ribbed or ribbed-grooved walls. ASME J. Heat Transfer. 116, 58-65.

Fig.9. Performance index Vs Reynolds for relative groove position $(\mathrm{g} / \mathrm{p})$ of 0.65 and wedge angle of $15^{\circ}$ \& e/D of 0.033 .

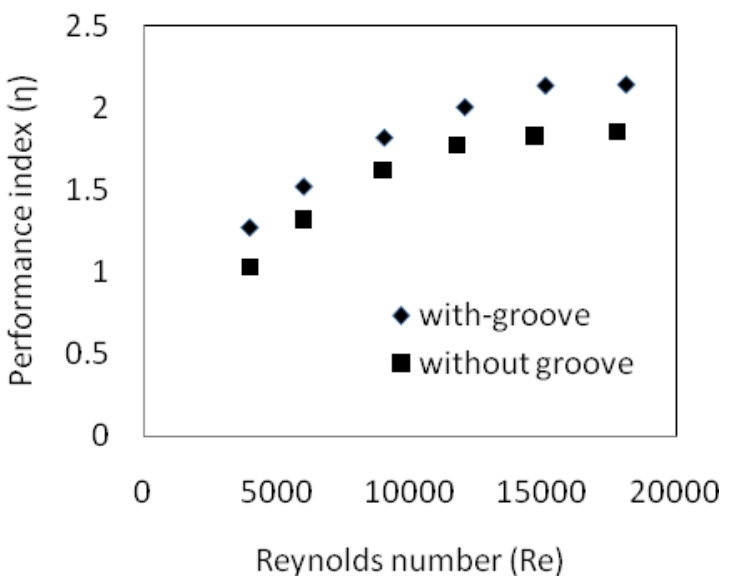

